\title{
Intra-amygdala injections of corticotropin releasing factor facilitate inhibitory avoidance learning and reduce exploratory behavior in rats
}

\author{
K.C. Liang ${ }^{1}$ and Eminy H.Y. Lee ${ }^{2}$ \\ ${ }^{1}$ Department of Psychology, National Taiwan University, and \\ ${ }^{2}$ Institute of Biomedical Sciences, Academia Sinica, Taipei, Taiwan, 11529, The Republic of China
}

\begin{abstract}
The effects of intra-amygdala injections of corticotropin-releasing factor (CRF) on memory and exploratory behavior in rats were examined in the present study. Rats with chronically implanted cannulae received intraamygdala injections of vehicle or CRF at a dose of 0.01 , 0.1 or $1.0 \mu \mathrm{g}$, either immediately after the inhibitory avoidance training or prior to the open field activity test. Results indicated that while CRF at low $(0.01 \mu \mathrm{g})$ and high $(1.0 \mu \mathrm{g})$ doses produced no significant effect on retention or exploration, immediate post-training intra-amygdala injections of $\mathrm{CRF}$ at the medium dose $(0.1 \mu \mathrm{g})$ significantly improved retention of the inhibitory avoidance response. The same dose of CRF, given shortly prior to the open field activity test, decreased locomotor activity, rearing and hole-poke responses in rats. These results suggest that the amygdala is one of the anatomical loci involved in CRF modulation of memory processing and exploration in rats. The implication of CRF in mediating the influences of stress on behavior is discussed.
\end{abstract}

Key words: Amygdala - Corticotropin releasing factor Exploration - Memory modulation - Open field - Rat

Corticotropin-releasing factor (CRF) is a 41-amino acid peptide originally identified by Vale et al. (1981), which has potency in releasing adrenocorticotropin (ACTH) as well as $\beta$-endorphin. Recent findings indicate that CRF is involved in extensive neurobehavioral functions other than regulating the pituitary-adrenal axis. Anatomically, CRF immunoreactive positive cell bodies or terminals have been demonstrated in various brain regions in addition to the hypothalamus (Palkovits et al. 1985). Central administration of CRF induces a wide spectrum of autonomic and behavioral changes, such as elevating plasma levels of catecholamines and glucose (Brown et al. 1982), alterations of cardiovascular responses (Fisher et al. 1983), increased locomotion and grooming in an open field environment (Veldhuis and De Wied 1984) and inhibition of feeding (Krahn et al. 1986) as well as sexual behavior (Sirinathsinghji et al. 1983). These findings lead to a suggestion that CRF may, at least partially, mediate the effects of stress on behavioral arousal (Koob and Bloom 1985).

Evidence supporting this notion, among others, is our recent findings that centrally administered CRF, like stress,

Offprint requests to: E.H.Y. Lee preferentially increases center region activity of mice in an open field (Lee et al. 1986, 1987). It has also been proposed that neurohormones released under stress may serve as endogenous learning/memory modulators (McGaugh 1983). Previous studies have shown that post-training intra-cerebroventricular (i.c.y.) injections of CRF impair $24 \mathrm{~h}$ retention performance in an inbibitory avoidance task (Veldhuis and De Wied 1984) and pre-training i.c.v. injections of CRF enhance acquisition/retention of a visual discrimination response (Koob and Bloom 1985).

Despite the profound effects of CRF on behavior, the exact anatomical sites responsible for the behavioral actions of centrally administered CRF is yet unknown. The finding (Eaves et al. 1985) that increased locomotion caused by CRF persists in the hypophysectomized rats rules out the participation of the pituitary gland in this effect (Sutton et al. 1982). Veldhuis and De Wied (1984) have also shown that the effects of i.c.v.-injected CRF on memory could not be attributed to the release of $\mathrm{ACTH}$ or corticosteroids. In view of the extensive extra-hypothalamic distribution of CRF and its receptors in the brain (Palkovits et al. 1985; De Souza 1987), it is important to address the question of where in the brain CRF may act to affect emotion-related behavior.

The amygdala has been implicated in modulating learning and memory processes (Sarter and Markowitsch 1985). Post-training chemical or electrical stimulation of the amygdala produces profound enhancing or impairing effects on retention of various learned responses (Handwerker et al. 1974; Gold et al. 1976; Gallagher et al. 1981; Liang and McGaugh 1983; Liang et al. 1986). Recent evidence further indicates that the amygdala is involved in the memory modulating effect of various neurohumoral factors such as ACTH, vasopressin (Van Wimersma Greidanus et al. 1979), epinephrine (Liang et al. 1986) and naloxone (McGaugh et al. 1988). The amygdala is also suggested to be involved in certain aspects of emotion-related behavior including exploration (Coulombe and White 1978). For example, Hitchcock and Davis (1986) have found that lesions of the amygdala block the conditioned fear response as measured with the potentiated startle paradigm. In view of the relatively high concentration of CRF in the central amygdaloid nucleus and substantially dense CRF receptors in the basolateral amygdaloid nucleus (Palkovits et al. 1985; De Souza et al. 1985), the present study was designed to investigate the effects of CRF injected into the amygdala on retention of an inhibitory avoidance task and on exploratory behavior in rats. 


\section{Materials and methods}

Subjects. Male Sprague-Dawley rats (60-70 days old, 180-230 g) purchased from the breeding center of National Yang-Ming Medical College were individually housed upon arrival and maintained on a $12 / 12 \mathrm{~h}$ light-dark cycle (lights on at 6:30 a.m.) with food and water ad lib. A total of 51 rats were used in the present study.

Surgery. Approximately 2-3 weeks after arrival, all rats were subjected to stereotaxic surgery. Under sodium pentobarbital $(40 \mathrm{mg} / \mathrm{kg})$ anesthesia, 23 gauge stainless steel thinwall cannulae $(15 \mathrm{~mm}$ long) were implanted bilaterally into the amygdala. The cannula tip was aimed at the dorsal surface of the amygdala complex (A.P. $-1.0 \mathrm{~mm}$ from Bregma, M.L. $\pm 4.5 \mathrm{~mm}$ from midline, D.V. $-7.0 \mathrm{~mm}$ below the skull surface; the nose bar was at $+5.0 \mathrm{~mm}$ ). Two small stainless steel screws serving as anchors were implanted over the right frontal and left posterior cortices. The cannulae were affixed on the skull with dental cement. A stylet was inserted into each cannula to maintain patency.

Inhibitory avoidance task. Two weeks after the surgery, rats were trained on a one-trial step through inhibitory avoidance task. The apparatus consisted of a trough-shape alley divided by a sliding door into an illuminated safe compartment and a dark shock compartment. The rat was placed into the safe compartment facing away from the door. As the rat turned around, the door was opened. After the rat entered the dark compartment, the door was closed and a $0.9 \mathrm{~mA} / 1 \mathrm{~s}$ footshock was administered. The shock intensity was calculated as the root mean square of sinusoidal currents. The rat was removed from the alley about $5 \mathrm{~s}$ after receiving the shock, administered the appropriate post-training treatments, and returned to its home cage. On the retention test given $24 \mathrm{~h}$ later, the rat was again placed into the illuminated compartment and the latency to step into the dark compartment was recorded as a measure of retention performance. Rats which did not enter the dark compartment within $600 \mathrm{~s}$ were removed from the alley and assigned a ceiling score of 600 .

Exploratory behavior measure. The exploratory behavior was monitored in two separate open field devices as described previously (Lee 1985). Briefly, each open field was 18 in. in diameter, with a stainless steel wall 15 in. high measured from the perimeter floor. A $4 \times 4$ perpendicular array of infrared photobeams $5 / 8 \mathrm{in}$. above the floor was used to localize the animal's floor position. There were also 18 wall holes located 5 in. above the floor and each hole was $4 / 5$ in. in diameter. These holes were designed for measuring the animal's hole-poke response. In addition to locomotor activity and hole-poke, animal's rearing frequency was also included in the exploration measure. For activity measurement, this behavioral apparatus was connected to a control unit to check the status of the beams and circuits in each open field. Any change of locomotion during the test was automatically taken by the control unit and displayed on the printer. The rearing and hole-poke responses were recorded by a human observer. The behavioral testing lasted for $30 \mathrm{~min}$ and data were collected and printed out every 6 min. The exploratory behavior was monitored in the light phase of the diurnal cycle.

Intra-amygdala drug administration. Animals received bilateral intra-amygdala injections of vehicle (Veh), 0.01, 0.1

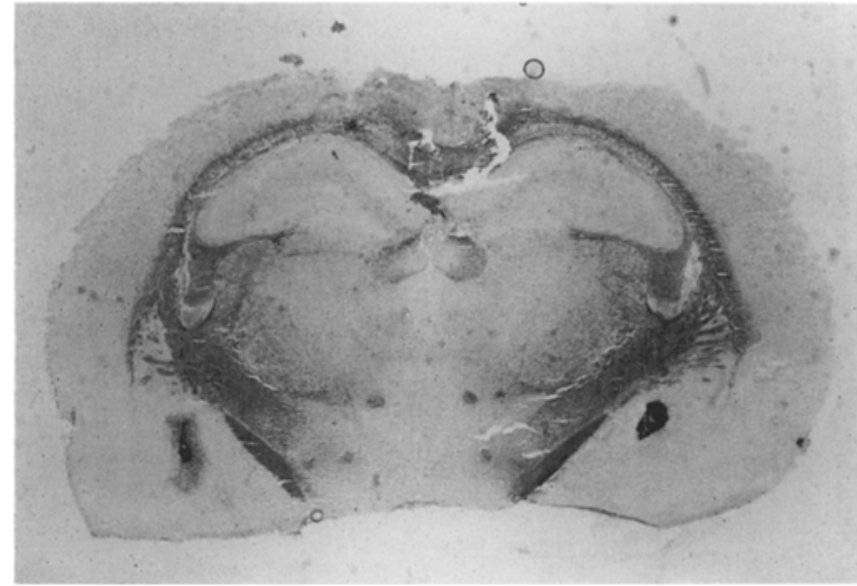

Fig. 1. The typical placement of injection needles in the amygdala of a representative rat. Methylene blue dye $1.5 \mu l(3 \mathrm{mg} / \mathrm{ml})$ was infused to the amygdala bilaterally. A $20-\mu \mathrm{m}$ thick section through the amygdala is shown

or $1.0 \mu \mathrm{g}$ CRF immediately after the inhibitory avoidance training. The animal was awake and gently held by the experimenter when receiving injections. The injection was administered through a 30-gauge injection needle connected to a $10 \mu$ Hamilton microsyringe by $0.5 \mathrm{~m}$ polyethylene tubing (PE-20). The injection needle was bent at a length such that, when inserted into the cannula, the needle tip would protrude $1.5 \mathrm{~mm}$ beyond the tip of the cannula. Drug solutions were introduced into the PE tubing and the microsyringe, and were delivered into the amygdala manually at a rate of $1 \mu \mathrm{l} / \mathrm{min}$. CRF was purchased from Research Biochemicals Incorporated and dissolved in saline, $1 \mu 1$ $\mathrm{CRF}$ or Veh was injected into each amygdala. One week after the inhibitory avoidance task, the animals were randomly re-assigned to four groups and received the same intra-amygdala injections of Veh, $0.01,0.1$ or $1.0 \mu \mathrm{g} C R F$ again. Three animals whose cannula complex fell off after the first experiment were not included in the second experiment. Immediately after the second CRF administration, animals were placed in an open field and their exploratory behavior was monitored.

Histology. After exploratory behavioral testing, animals were sacrificed by decapitation and the brains were removed. For histological examination of cannula and needle placement in the amygdala, the brains were frozen-sectioned in a cryostat and checked individually. Twentymicron thick sections taken at $50 \mu \mathrm{m}$ intervals through the amygdala were mounted on slides and stained with thionine blue. Animals were accepted for data analysis if both needle placements were located within the amygdala according to the atlas by Paxinos and Watson (1986). Figure 1 illustrates the placement of the needle position in the amygdala under microscopic examination.

Statistics. Since the distribution of retention scores was truncated at 600 , nonparametric Mann-Whitney two-tailed $U$ tests were used to analyze the data for the inhibitory avoidance task. Locomotor activity, rearing and hole-poke responses were analyzed by a two-way mixed design analysis of variance (ANOVA) with "treatment" as the betweensubjects factor and "time" as the repeated measures. Spe- 


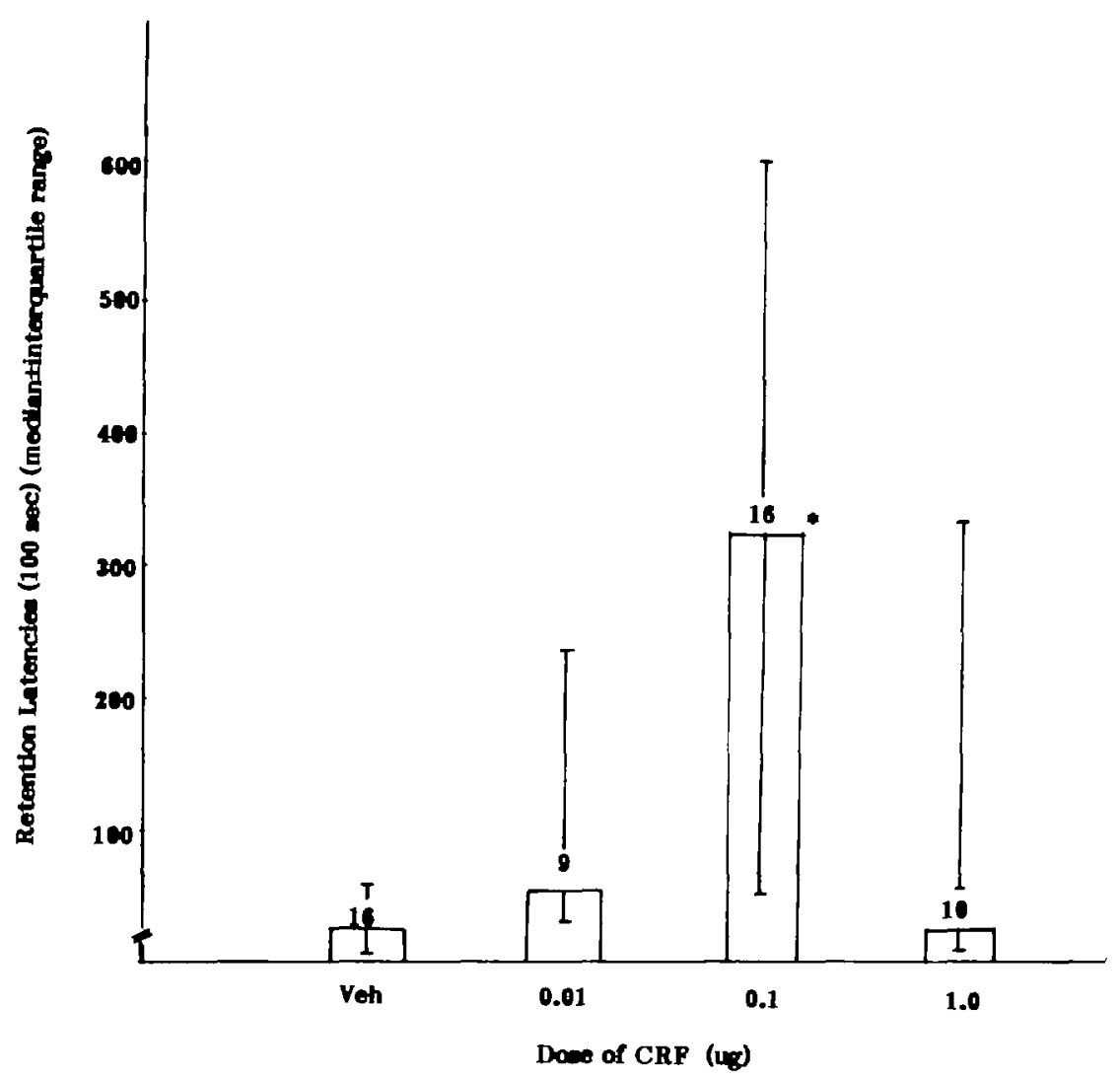

Fig. 2. Retention performance of rats receiving intra-amygdala injections of vehicle, $0.01,0.1$ or $1.0 \mu \mathrm{g} \mathrm{CRF}$. $* P<0.05$, MannWhitney two-tailed $U$ tests

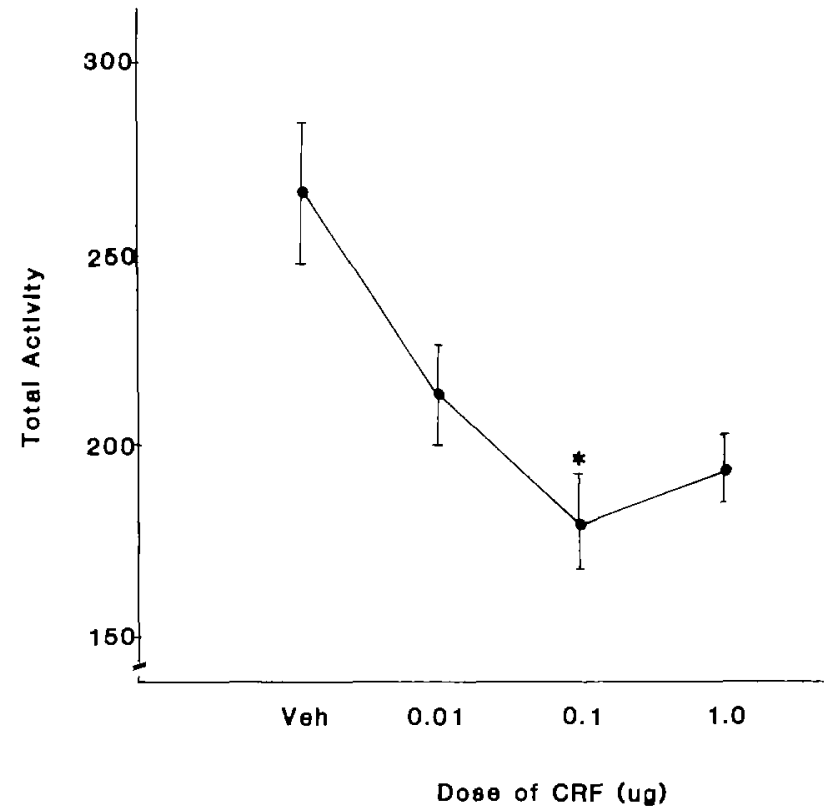

Fig. 3. Effects of intra-amygdala injections of CRF on locomotor activity in rats $\left(n=12\right.$ each). ${ }^{*} P<0.01$, Dunnett's $t$-tests

cific comparisons between each treatment group and a common control group were made with the Dunnett's method (Winer 1971).

\section{Results}

Retention performance of various groups of rats in the inhibitory avoidance task is shown in Fig. 2. Mann-Whitney

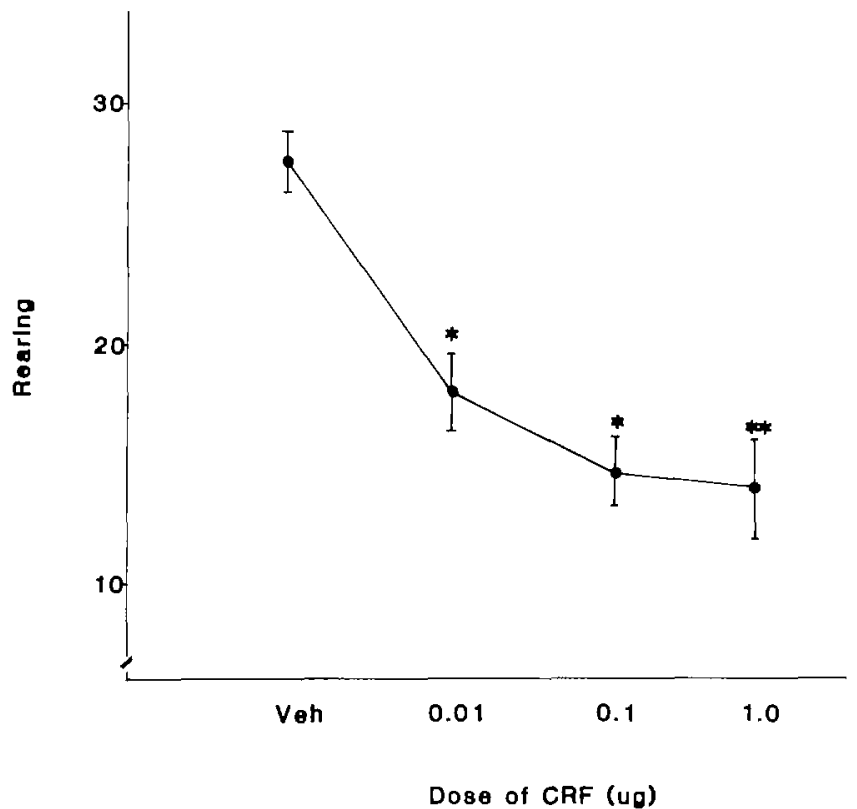

Fig. 4. Effects of intra-amygdala injections of CRF on rearing response in rats $\left(n=12\right.$ each). ${ }^{*} P<0.05,{ }^{* *} P<0.01$, Dunnett's $t$-tests

two-tailed $U$ tests indicated that $0.1 \mu \mathrm{g}$ CRF injected into the amygdala immediately after training enhanced retention: rats receiving $0.1 \mu \mathrm{g} C R F$ showed significantly better retention performance than the Veh-injected group ( $U=75$, $P<0.05)$. CRF at $0.01 \mu \mathrm{g}$ and $1.0 \mu \mathrm{g}$ did not have any significant effect upon retention ( $P>0.05$, ns).

Effects of intra-amygdala CRF on activity, rearing and hole-poke measures are shown in Fig. 3, Fig. 4 and Fig. 5, 


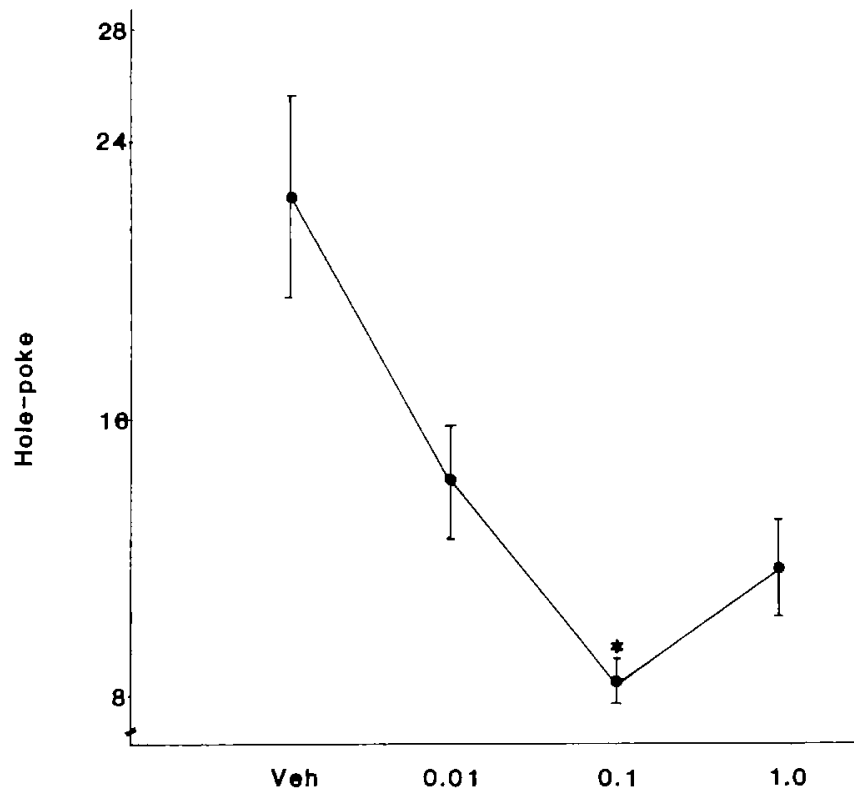

Fig. 5. Effects of intra-amygdala injections of CRF on hole-poke frequency in rats $(n=12 \mathrm{each}){ }^{*} P<0.05$, Dunnett's $t$-tests

respectively. As shown in Fig. 3, while the overall main effect of CRF on activity was not significant $(F=1.83, d f=$ $3,33, P>0.05$ ), further analyses revealed that CRF at $0.1 \mu \mathrm{g}$ significantly decreased locomotor activity $(t D=2.16, P<$ $0.05)$. As indicated in Fig. 4, CRF dose-dependently decreased rearing in rats $(F=3.82, d f=3,33 ; P<0.05)$. Individual comparisons revealed that $\mathrm{CRF}$ at each of the doses examined had a significant effect $(t D=2.14, P<0.05$ for $0.01 \mu \mathrm{g} \mathrm{CRF} ; t D=2.82, P<0.05$ for $0.1 \mu \mathrm{g} \mathrm{CRF}$ and $t D=$ 2.96, $P<0.01$ for $1.0 \mu \mathrm{g}$ CRF). As revealed in Fig. 5, similar to its effects on locomotor activity, CRF at $0.1 \mu \mathrm{g}$ also markedly reduced the hole-poke frequency $(t D=2.57, P<$ $0.05)$.

\section{Discussion}

The present results indicate that intra-amygdala injections of CRF significantly improved retention of an inhibitory avoidance response when given shortly after training and depressed specific aspects of activity when given shortly prior to the open field test. Furthermore, in both cases, the effects of CRF injected into the amygdala were dose dependent, with the medium dose $(0.1 \mu \mathrm{g})$ being the most effective. While the mechanism underlying this U-shaped dose-response curve is not immediately clear, it is often found in the effects of stressors or stress-related hormones on behavior (Price and Cooper 1975; McGaugh 1983; Martinez 1986). This "non-monotonic" dose-response function of CRF in modulating memory or activities is similar to that demonstrated in the effects of CRF or footshock stress in modulating the startle response (Davis and Astrachan 1978; Swerdlow et al. 1986). The present findings thus suggest that the amygdala may be involved in the effects of CRF on the emotion-related behavior.

The post-training treatment paradigm in the inhibitory avoidance task rules out the possibility that CRF could have affected sensori-motor abilities or motivational states of the animal during the phase of acquisition. The enhanced retention is unlikely to be due to the depressed locomotor activity induced by CRF, since the retention test was conducted $24 \mathrm{~h}$ after the administration of CRF, by which time the influences of CRF on activity would have presumably dissipated (Koob et al. 1984). In view of the evidence that CRF is released into the portal blood under various stressful situations (Nakane et al. 1985) and presumably may also be released in the central nervous system, the present findings provide further support for the notion that stressrelated neurohormonal factors could act as potent endogenous memory modulators in certain learning situations (McGaugh 1983).

While the present results are consistent with the previous findings that i.c.v. injections of CRF $(0.15 \mathrm{nM})$ enhanced acquisition/retention performance in the visual discrimination task (Koob and Bloom 1985), they are in contrast to the findings of Veldhuis and De Wied (1984), who reported that post-training or pre-testing i.c.v. administration of a very low dose $(30 \mathrm{pg})$ of CRF impaired retention of a step-down inhibitory avoidance response. The discrepant results may imply that CRF injected i.c.v. acts predominantly on a site other than the amygdala to impair memory. Alternatively, the discrepancy may be due to some subtle differences in the learning paradigm and/or the dosage of the drug used. It should be pointed out that retention performance of the saline group is much higher in the study of Veldhuis and De Wied (1984) than in ours. It is well documented that for various memory modulating treatments, retention facilitation is more readily demonstrated under low performance of the control group while retention impairment is more readily demonstrated under high performance of the control group (for review, see McGaugh 1983).

The present results indicate that CRF at a moderate dose decreased activity, rearing and hole-poke responses of rats in an open field. While the effects of CRF on activity are incongruent with some studies showing that i.c.v. CRF increases locomotion, they are consistent with the reports that CRF enhances effects of novelty on behavior, including decreasing the amount of rearing and food intake in an open field (Britton et al. 1982). The present results are also consistent with the findings that CRF produces behavioral activation in a familiar environment but produces behavioral inhibition in a novel situation in rats (Koob et al. 1984). It is likely that the intra-amygdala CRF injection elevates emotionality and fear/anxiety in animals and consequently, decreased exploratory behavior in a novel environment. This explanation is supported by the findings that lesions of the amygdala block the conditioned fear response in rats as measured with the potentiated startle paradigm (Hitchcock and Davis 1986). It is also possible that CRF injected i.c.v. may act on different anatomical sites to affect exploration differentially.

The present results suggest that the amygdala may be an effective site for CRF to act on memory processing and exploration. However, it remains to be elucidated how CRF in the amygdala modulates these aspects of behavior. CRF may activate neurons or fiber tracts in the amygdala which are somehow involved in memory processing and exploration. Alternatively, CRF in the amygdala may affect these behaviors through some indirect mechanisms. Although the amygdala has been implicated in regulating ACTH release (Feldman et al. 1982), previous findings have ruled out the involvement of the pituitary functions in these effects (Veldhuis and De Wied 1984; Eaves et al. 1985). Electrical stimu- 
lation of the amygdala may induce release of adrenal epinephrine (Reis and Gunne 1965). Central administration of CRF has also been shown to increase sympathetic outflow, including elevating plasma epinephrine (Brown et al. 1982). These findings raise the possibility that CRF, by stimulating the amygdala, may activate the release of epinephrine which in turn modulates various aspects of emotion-related behavior, including aversive learning and exploration. This issue should be addressed in future studies.

Acknowledgements. This work was supported by the research fund from the Institute of Biomedical Sciences, Academia Sinica. Dr K.C. Liang was supported by National Taiwan University and Dr Eminy H.Y. Lee was supported by the Institute of Biomedical Sciences, Academia Sinica.

\section{References}

Britton DR, Koob G, Rivier J, Vale W (1982) Intraventricular corticotropin-releasing factor enhances behavioral effects of novelty. Life Sci 1:363-367

Brown R, Fisher LA, Speis J, Rivier J, Rivier C, Vale W (1982) Corticotropin-releasing factor: actions on the sympathetic nervous system and metabolism. Endocrinology 111:928-931

Coulombe D, White N (1978) Effects of lesions of the amygdala, pyriform cortex, and stria terminalis on two types of exploration by rats. Physiol Psychol 6:319-324

Davis M, Astrachan D (1978) Conditioned fear and startle magnitude: effects of different footshock or backshock intensities used in training. J Exp Psychol 4:95-103

De Souza EB (1987) Corticotropin-releasing factor receptors in the rat central nervous system; characterization and regional distribution. J Neurosci 7:88-100

De Souza EB, Insel TR, Perrin M, Rivier J, Vale WW, Kuhar MJ (1985) Corticotropin-releasing factor receptors are widely distributed within the rat central nervous system : an autoradiographic study. J Neurosci 12:3189-3203

Eaves M, Britton T, Rivier J, Vale W, Koob G (1985) Effects of corticotropin releasing factor on locomotor activity in hypophysectomized rats. Peptides 6:923-926

Feldman S, Conforti N, Siegel RA (1982) Adrenocortical responses following limbic stimulation in rats with hypothalamic deafferentation. Neuroendocrinology $35: 205-211$

Fisher LA, Jonssen G, Brown MR (1983) Corticotropin-releasing factor (CRF): mechanism to elevate mean aterial pressure and heart rate. Regul Pept 5:153-161

Gallagher M, Kapp BS (1981) Influence of amygdala opiate-sensitive mechanisms, fear-motivated responses, and memory processes for aversive experiences. In: Martinez JL Jr, Jensen RA, Messing RB, Rigter H, McGaugh JL (eds) Endogenous peptides and learning and memory processes. Academic Press, New York, p 445

Gold PE, Rose RP, Hankins LL, Spanis C (1976) Imparred retention of visual discriminated escape training produced by subseizure amygdala stımulation. Brain Res 118:73-85

Handwerker MJ, Gold PE, McGaugh JL (1974) Impairments of active avoidance learning with posttraining amygdala stimulation. Brain Res 75:325-327

Hitchcock J, Davis M (1986) Lesions of the amygdala, but not of the cerebellum or red nucleus, block conditioned fear as measured with the potentiated startle paradigm. Behav Neurosci $100: 11-22$

Koob GF, Bloom FE (1985) Corticotropin-releasing factor and behavior. Fed Proc 44:259-263

Koob GF, Le Moal M, Bloom FE, Sutton RE, Rivier J, Vale W (1984) Corticotropin releasing factor produced behavioral activation and improves learning in rats. Neurosci Abstr 10:145
Krahn DD, Gosnell A, Grace M, Levine AS (1986) CRF antagonist partially reverse CRF and stress-induced effects on feeding. Brain Res Bull 17:285-289

Lee EHY (1985) Effects of nicotine on exploratory behavior in rats: correlation with regional brain monoamne levels. Behav Brain Res 17:59-66

Lee EHY, Tsai MJ, Cha1 CY (1986) Stress selectively influences center region activity of mice in an open field. Physiol Behav 37:659-662

Lee EHY, Tang YP, Cha1 CY (1987) Stress and corticotropinreleasing factor potentiate center region activity of mice in an open field. Psychopharmacology (in press)

Liang KC, McGaugh JL (1983) Lesions of the stria terminalis attenuate the amnestic effect of posttraining amygdala stimulation on avoidance responses. Brain Res 274:309-318

Liang KC, Juler RG, McGaugh JL (1986) Modulation effect of posttraining epinephrine on memory: involvement of the amygdala noradrenergic system. Brain Res 368:125-133

Martinez JL Jr (1986) Memory drugs and hormones. In: Martinez $\mathrm{JL} J \mathrm{~J}$, Kesner RP (eds) Learning and memory: a biological view. Academic Press, Orlando, p 127

MoGaugh JL (1983) Hormonal influences on memory. Annu Rev Psychol 27:297-323

McGaugh JL, Introini-Collison I, Nakahara A (1988) Memoryenbancing effects of posttraining naloxone: involvement of $\beta$ noradrenergic influences in the amygdaloid complex. Brain Res $446: 37-49$

Nakane T, Audhya T, Kanic N, Hollander CS (1985) Evidence for a role of endogenous corticotropin-releasing factor in cold, ether, immobilization, and traumatic stress. Proc Natl Acad Sci USA 82:1247-1251

Palkovits M, Brownstein MJ, Vale W (1985) Distribution of corticotropin-releasing factor in rat brain. Fed Proc 44:215-220

Paxinos G, Watson C (1986) The rat brain in stereotaxic coordinates. 2nd ed. Academic Press, Orlando

Price MTC, Cooper RM (1975) U-shaped functions in a shock escape task. J Comp Physiol Psychol 80:600-606

Reis DJ, Gunne LM (1965) Brain catecholamines: relation to the defense reaction evoked by amygdala stimulation in the cat. Science 149:450-451

Sarter M, Markowitsch HJ (1985) Involvement of the amygdala in learning and memory: a critical review, with emphasis on anatomical relations. Behav Neurosci 99:342 -380

Sirinatbsinghji DJS, Rees LH, Rivier J, Vale W (1983) Corticotropin-releasing factor (CRF) is a potent inhibitor of sexual receptivity in the female rat. Nature 305:230-235

Sutton R, Koob G, Le Moal M, Rivier J, Vale W (1982) Corticotropin-releasing factor (CRF) produces behavioral activation in rats. Nature 297:331-333

Swerdlow NR, Geyer MA, Vale WW, Koob GF (1986) Corticotropin-releasing factor potentiates acoustic startle in rats: blockade by chlordiazepoxide. Psychopharmacology 88:147-152

Vale W, Speis J, Rivier C, Rivier J (1981) Characterization of a 41-residue ovine hypothalamic peptide that stimulates secretion of corticotropin and beta-endorphin. Science 213:1394-1397

Van Wimersma TjB, Coriset G, Bokker E, Bowman H (1979) Amygdaloid lesions block the effect of neuropeptides (vasopres$\sin$ and ACTH) on avoidance behavior. Physiol Behav 22: 291-295

Veldhuis HD, De Wied D (1984) Differential behavioral actions of corticotropin-releasing factor (CRF). Pharmacol Biochem Behav $21: 707-713$

Winer B (1971) Statistical principles in experımental design. McGraw-Hill, New York

Received December 9, 1987 / Final version June 2, 1988 